\title{
Comparing WHO C-Model generated C-Section probabilities to actual delivery outcomes in a tertiary care centre
}

\author{
Amita Ray ${ }^{1 *}$, Arun Gopi², Sujoy Ray $^{3}$
}

\begin{abstract}
${ }^{1}$ Department of Obstetrics and Gynecology, ${ }^{2}$ Department of Community Medicine, DM Wayanad Institute of Medical Sciences, Wayanad, Kerala, India

${ }^{3}$ Department of Psychiatry, St. John's Medical College, Bangalore, Karnataka, India
\end{abstract}

Received: 07 November 2017

Accepted: 02 December 2017

*Correspondence:

Dr. Amita Ray,

E-mail: amitarays@gmail.com

Copyright: (c) the author(s), publisher and licensee Medip Academy. This is an open-access article distributed under the terms of the Creative Commons Attribution Non-Commercial License, which permits unrestricted non-commercial use, distribution, and reproduction in any medium, provided the original work is properly cited.

\section{ABSTRACT}

Background: A model which takes into account several relevant factors and gives the probability of C-Section in a woman would have the advantage of preparing for such an event. The identification of women at high risk of CSection ( $>50 \%$ risk) would provide the opportunity for understanding risks involved in pursuing a vaginal delivery whereas if the risk of C-Section was less $(<50 \%)$ it would prove useful in counselling for a vaginal delivery. We used the WHO C-Model with the aim to find the predictability of this model in our facility and the overuse of C-section in the 10 Robson's Groups.

Methods: A retrospective observational study in which all women who gave birth at our hospital from June 2016 to May 2017 were included and C-Section probability was calculated using the C-Model. Comparison with the actual mode of delivery was done to find the sensitivity, specificity, positive and negative predictive value of the model and the overuse of C-Section in the Robson's Groups.

Results: Out of the 314 C-Sections done only 45 women had a $>50 \%$ probability, giving the model a sensitivity of $14.33 \%$, specificity of $98.8 \%$, positive predictive value of $90 \%$ and negative predictive value of $60.56 \%$. Robson's Groups 5 and 3 demonstrated the greatest overuse of C-Sections.

Conclusions: The WHO Model when applied to this centre showed a high positive predictive value for C-Sections but the negative predictive value or the ability to correctly predict a vaginal delivery was much less.

Keywords: C-Model, Negative predictive value, Positive predictive value, Robson's Groups

\section{INTRODUCTION}

Rising C-Section rates have been a matter for major concern all over the world. ${ }^{1-5}$ In 1985 WHO stated that a C-section rate of above $15 \%$ is not justifiable at the same time stressed that every effort be made to provide CSection when needed rather than aim for a particular rate. ${ }^{6}$ It is very difficult at the level of an individual health care facility, particularly tertiary care centre to determine an appropriate rate of $\mathrm{CS} .{ }^{4}$ When it comes to such centres the C-Section rates have been found to be universally higher both in the developed and the developing worlds. ${ }^{1-4}$ The reason could be due to differences in the cases that that they deal with depending upon their geographical location, the obstetric profile of the cases, social and logistical factors This would make it difficult to have a generalized or uniformly appropriate C-Section rate. ${ }^{1-5}$

Since it is desirable that C-section should be definitely done when indicated at the same time the rate be kept at a minimum, it would be helpful for clinicians to know what 
could be the probability of an operative delivery in an individual case. ${ }^{6}$ This would help the whole healthcare team as well as the woman and her family to prepare both mentally and physically for the forthcoming birth process. Centres where facilities for operative delivery are not available would be able to refer such cases where the probability of a C-Section was high. Even for centres where facilities are available it would be good to know the probability of C-Section. Where probabilities were high an elective section could be offered knowing that maternal and foetal outcomes are better in elective versus emergency C-Sections. ${ }^{7-9}$

Many studies have retrospectively looked at predictors of C-Section and have found social, demographic, prenatal and other factors associated with risks for and a high incidence for C-Section delivery. ${ }^{10-13} \mathrm{~A}$ model which takes into account several relevant factors and prospectively gives the probability of C-Section would have the advantage of preparing for such an event. It can provide an individualized assessment of the risk of $\mathrm{C}$ Section which can better inform women in preparation for childbirth and may be useful in managing women's expectations. The identification of women at high risk of C-Section ( $>50 \%$ risk) would also provide the opportunity for informed decision making about the risks associated with a vaginal delivery versus an elective CSection. As maternal request for $\mathrm{C}$-Section without specific maternal or fetal indication becomes more common, this risk assessment tool may also prove useful in counselling women with low risk to opt for a vaginal delivery. ${ }^{14}$

With this aim in mind we applied the WHO devised CModel in our population to assess the probability of CSection and compare this with the actual outcome. The WHO C Model adds socio-demographic data, severity markers and complications to the clinic-obstetrical data of the Robson's classification as predictors to calculate the probability of $\mathrm{C}$-Section in an individual patient. ${ }^{6}$

Using this Model to calculate C-section probabilities would help in assessing the utility of this model as regards its predictability. It would also help the health care team to identify the Robson's Groups where the outcome (mode of delivery) coincided with the C-Model predicted probability and in which groups it did not. This information could then be utilized to develop a realistic approach towards reduction of $\mathrm{C}$-section rates at the same time ensure that it is readily provided when the need arises. It would also help identify other factors which need to be considered when calculating or assessing the probability of C-Section in an individual woman.

Objective of present study were to determine the predictive utility of the C-Model in terms of sensitivity, specificity, positive and negative predictive value of the C-Model when applied to our health care facility and to use the C-Model to find the use and overuse of C-section in the 10 Robson's Groups.

\section{METHODS}

A retrospective observational study included women admitted for delivery at a teaching hospital in Wayanad, Kerala, India from June 2016 to May 2017. We calculated the overall C-Section rates as well as the percentage of C-Sections in each Robson's Group to assess which Groups were the major contributors to the C-Sections. From each case file the demographic, obstetric and complicating factor information was fed into the Caluladora to get the probability of C-Section as per the WHO C-Model. All the subjects with a WHO CModel probability of $>50 \%$ have been considered as patients who need $\mathrm{C}$-Section and women with probability $<50 \%$ has been considered as patients who did not need a C-Section. The WHO model is basically a Logistic regression model and the logistic regression analysis usually considers the $50 \%$ as the cut off value

A sensitivity and specificity analysis were done to compare the WHO probability with the actual mode of delivery outcome in our women. The actual outcome has been considered as the reference and the WHO C-Model calculated probability (based on the cut off value of 50\%) has been compared with it. In each of the 10 Robson's Groups we identified the number and percentage of pregnant women with a WHO calculated probability of $<50 \%$ who underwent a C-Section to identify which Robson's Group exhibited overuse of C-Section.

\section{RESULTS}

Robson's group 6 had a considerably a lower average age $(22.78 \pm 3.96)$.

Table 1: Age, frequency and percentage of Robson's groups.

\begin{tabular}{|llll|}
$\begin{array}{l}\text { Robson's } \\
\text { Group }\end{array}$ & Number & $\%$ & $\begin{array}{l}\text { Mean age and } \\
\text { standard deviation }\end{array}$ \\
\hline Group 1 & 144 & 19.6 & $24.31 \pm 4.921$ \\
\hline Group 2 & 94 & 12.8 & $23.45 \pm 3.726$ \\
\hline Group 3 & 214 & 29.23 & $27.45 \pm 4.224$ \\
\hline Group 4 & 83 & 11.33 & $27.63 \pm 4.233$ \\
\hline Group 5 & 108 & 14.75 & $27.81 \pm 4.095$ \\
\hline Group 6 & 9 & 1.22 & $22.78 \pm 3.962$ \\
\hline Group 7 & 3 & 0.40 & $27.33 \pm 5.033$ \\
\hline Group 8 & 7 & 0.95 & $25.86 \pm 4.059$ \\
\hline Group 9 & 1 & 0.13 &. \\
\hline Group 10 & 69 & 9.42 & $25.12 \pm 5.007$ \\
\hline
\end{tabular}

Majority of the subjects belonged to Group 3 followed by Group 1 (29.1\% and $19.6 \%$ respectively), together both groups accounted for $48.7 \%$ of the population of pregnant women who had live births at our hospital. The number of subjects was least in group 9 and 7 (less than $1 \%$ in each) (Table 1). A total of 732 deliveries took place in our centre during last year out of which 314 were CSections and 428 were vaginal births giving a C-Section rate of $43 \%$ (Table 2). 
Table 2: Frequency and percentage of delivery outcomes.

\begin{tabular}{|lll|}
\hline & Frequency & Percentage \\
\hline Vaginal & 418 & 57.10 \\
\hline C-section & 314 & 42.89 \\
\hline Total & 732 & 100.00 \\
\hline
\end{tabular}

Group number 5 and 3 had the highest absolute number of C-Sections. (93 and 60 respectively). Percentage wise the greatest percentage of C-Sections was done in Group 5 and Group 8 (86.1\% and $71.4 \%$ respectively) (Table 3$)$.

Table 3: Frequency and percentage of delivery outcomes among different Robson's groups.

\begin{tabular}{|c|c|c|}
\hline Robson's Group & Frequency & Percentage \\
\hline Vaginal & 97 & 67.36 \\
\hline C-Section & 47 & 32.64 \\
\hline Total & 144 & 100.0 \\
\hline Vaginal & 51 & 54.25 \\
\hline C-Section & 43 & 45.75 \\
\hline Total & 94 & 100.0 \\
\hline Vaginal & 154 & 71.96 \\
\hline C-Section & 60 & 28.14 \\
\hline Total & 214 & 100.0 \\
\hline Vaginal & 61 & 73.49 \\
\hline C-Section & 22 & 26.51 \\
\hline Total & 83 & 100.0 \\
\hline Vaginal & 15 & 13.88 \\
\hline C-Section & 93 & 86.12 \\
\hline Total & 108 & 100.0 \\
\hline Vaginal & 3 & 33.33 \\
\hline C-Section & 6 & 66.67 \\
\hline Total & 9 & 100.0 \\
\hline C-Section & 3 & 100.0 \\
\hline Vaginal & 2 & 28.57 \\
\hline C-Section & 5 & 71.43 \\
\hline Total & 7 & 100.0 \\
\hline C-Section & 1 & 100.0 \\
\hline Vaginal & 45 & 65.21 \\
\hline C-Section & 24 & 34.79 \\
\hline Total & 69 & 100.0 \\
\hline
\end{tabular}

Table 5: Sensitivity and specificity of the C-Model for predicting our mode of delivery outcome.

\begin{tabular}{|c|c|c|c|c|c|}
\hline & & & \multicolumn{2}{|c|}{ Mode of delivery } & \multirow{2}{*}{ Total } \\
\hline & & & CS & Normal & \\
\hline \multirow{4}{*}{$\begin{array}{l}\text { Probability by } \\
\text { WHO C-Model }\end{array}$} & \multirow{2}{*}{ C-Section $(>50 \%)$} & Count & 45 & 5 & 50 \\
\hline & & $\%$ & 14 & 1 & \\
\hline & \multirow{2}{*}{ C-Section $(<50 \%)$} & Count & 269 & 413 & 682 \\
\hline & & $\%$ & 86 & 99 & \\
\hline \multirow{2}{*}{ Total } & & & 314 & 418 & 732 \\
\hline & & & 100 & 100 & \\
\hline
\end{tabular}

Groups 5 and 3 had the highest number of such cases who underwent a C-Section with a $<50 \%$ chance as calculated by the WHO-C Model ( $n=67$ and $n=61$ respectively) (Table 4).

Using the $50 \%$ cut off; Out of the $314 \mathrm{C}$ sections done, only 45 subjects needed to undergo a CS as per the WHO probability (Low sensitivity of the C-Model).

Out of the 418 subjects who had a normal delivery at DMWIMS, only 5 had a more than $50 \%$ chance of a CSection (High specificity of the C-Model).

Table 4: Frequency and percentage of C-Sections in each Robson's Group where the probability of CSection by WHO-Model was $<50 \%$.

\begin{tabular}{|lll|}
\hline Robson's groups & Frequency & Percentage \\
\hline 1 & 46 & 32.9 \\
\hline 2 & 44 & 47.8 \\
\hline 3 & 61 & 28.6 \\
\hline 4 & 22 & 26.5 \\
\hline 5 & 67 & 85.9 \\
\hline 6 & 2 & 25.0 \\
\hline 7 & 1 & 100.0 \\
\hline 8 & 2 & 66.7 \\
\hline 9 & none & \\
\hline 10 & 20 & 31.3 \\
\hline
\end{tabular}

The probability of the WHO Model to correctly predict a C-Section in our population was only $14 \%$ while the probability of predicting vaginal delivery was $98.8 \%$ quite high.

The positive predictive value was $90 \%$ (The probability that the subjects who were supposed to undergo CS as per WHO calculation truly underwent C-Section).

The negative predictive value was $60.56 \%$ (The probability that the subjects who were supposed to have a normal delivery as per WHO calculation truly had the same) (Table 5). 


\section{DISCUSSION}

Our overall C-Section rate for the study period was $43 \%$. This though higher than the WHO recommended rate is quite in accordance with those found at tertiary care centres in both developed and developing countries. ${ }^{15-18}$ This is probably because it is the biggest referral centre in the district and this rate reflects the hospital C-Section rate rather than the population $\mathrm{C}$-Section rate. To be truly reflective of the population $\mathrm{C}$-Section rate the live births in other hospitals which refer operative cases to our centre due to lack of facilities would have to be taken into account. This would be true for any tertiary care centre around the world. ${ }^{5}$

During the study period our centre had the highest number of women in Robson's Group 3 followed by Groups1 and 5. Studies done in other countries spanning different time periods have shown the same trend in the both the developed and the developing world. ${ }^{15,18}$

By way of contribution to the C-Section rate Group 5 followed by Group 3 had the highest contribution. Other such studies in the developed and developing world have found Group 5 to be the highest contributor followed by Group 1. ${ }^{15,18}$

As regards the application of the C-Model we would like to discuss our findings in two ways

Firstly, and considering the C-Model to be an accurate predictor of the route of delivery we will interpret our data as use and overuse of C-Section in our hospital Applying this Groups 5 and 3 (the two groups that are the largest contributors to the C-Section rates) have the greatest number of such cases who had a C-Section even though the calculated probability by the WHO C-Model was less than $50 \%$. Other studies in different settings have also found this variation between the C-Model predicted probability and the actual delivery outcome in the Robson's groups demonstrating an overuse of CSections. These studies have compared the mean predicted (by WHO Model) probability for each Robson's group to the mean of the actual outcome in each group. ${ }^{19-22}$ Present study reports on the absolute number of such cases in each Robson's Group where the predicted mode of delivery did not coincide with the actual outcome using a $50 \%$ cut off. Using the C-Model either of the two ways has demonstrated an overuse in different settings and to different extents.

Secondly, we used our data to consider the predictive utility of the C-Model when applied to our circumstances. We did a sensitivity and specificity calculation taking the actual mode of delivery outcome of our women as the gold standard. The specificity and positive predictive value of the C-Model was high, but the sensitivity and negative predictive value was low. We tried to identify factors or reasons why this may be so.
The greatest variation between the probability calculated by the WHO-C Model and the actual mode of delivery was observed in Group 5. This Group was also the second largest contributor to the total population of pregnant women who had live births. There were 144 women in this group out of which 93 underwent CSection. Among those who underwent C-Section there were 67 such women who by WHO C-Model calculation had a less than $50 \%$ probability of a C-Section The indications for $\mathrm{C}$-Section in these cases were foetal distress, dystocia or non progress, scar tenderness and CSection on demand or on request.

Out of these $67 \mathrm{C}$-Sections 25 were done for non progress of labor and 16 of these babies had a birth weight ranging from $3.7-4.5 \mathrm{~kg}$ (10 mothers had gestational diabetes). Another 12 of these $67 \mathrm{C}$-Sections were done on demand.

The C Model has not taken into consideration fetal anthropometric measurements. Studies looking at factors effecting C-Section rates and study authors developing predictive models for $\mathrm{C}$-Sections have considered this as an important variable. ${ }^{13,14}$ Present study also seems to be corroborating this. The specificity of the C-Model may be increased by incorporating this variable, particularly in context of the Group 5 which includes multiparous women with a previous scar. These women would also be likely to have gestational diabetes which is another reason for large babies.

Another variable that has come to light in this group is the on-demand C-Sections. This could be thought of a variable for a predictive value but could also be arguably an indicator for overuse

Some other variables have also been associated with increased C-Sections are maternal age height and BMI. ${ }^{13,14,20}$ We did not assess these variables in our study.

\section{CONCLUSION}

As reported by other such studies the use of the WHO-CModel could give important information about use and overuse of C-Sections in the 10 Robson's Groups This information could be used to optimize C-Section rates in health care facilities.

The WHO Model when applied to this centre showed a high positive predictive value for C-Sections but the negative predictive value or the ability to correctly predict a vaginal delivery was much less. The predictive utility of the C-Model could be increased by incorporating the important variables of foetal anthropometric measurements, maternal age and BMI. Accurate prediction of the mode of delivery would help increase preparedness for the event both for the mother and her family as well as the personnel at the health care facility. Increased preparedness would result in better maternal and neonatal outcomes. 
Funding: No funding sources

Conflict of interest: None declared

Ethical approval: The study was approved by the Institutional Ethics Committee

\section{REFERENCES}

1. Betran AP, Merialdi M, Lauer JA, Bing-Shun W, Thomas J, Van Look P, et al. Rates of caesarean section: analysis of global, regional and national estimates. Paediatr Perinat Epidemiol. 2007;21:98-113.

2. Zizza A, Tinelli A, Malvasi A, Barbone E, Stark M, De Donno A, et al. Caesarean section in the world: a new ecological approach. J Prev Med Hyg. 2011;52:161-73.

3. Litorp H, Kidanto H, Nystrom L, Darj E, Esse' n B. Increasing caesarean section rates among low-risk groups: a panel study classifying deliveries according to Robson at a university hospital in Tanzania. BMC Pregnancy Childbirth. 2013;13:107.

4. Souza JP, Betran AP, Dumont A, Mucio B, Pickens G, Deneux-Tharaux $\mathrm{C}$ et al. A global reference for caesarean section rates (C-Model): a multicountry cross-sectional study. BJOG. 2016;123:427-36.

5. Ray A, Jose S. Analysis of caesarean-section rates according to Robson's ten group classification system and evaluating the indications within the groups Int $\mathrm{J}$ Reprod Contracept Obstet Gynecol. 2017 Feb;6(2):44751.

6. WHO Statement on Cesarean section rates. Available at http://www.who.int/reproductivehealth/publications/mat ernal_perinatal_health/cs-statement/en/

7. Suwal A, Shrivastava VR, Giri A. Maternal and fetal outcome in elective versus emergency cesarean section. J Nepal Med Assoc. 2013 Oct- Dec;52(192):563-6.

8. Benzouina S, Boubkraoui ME, Mrabet M, Chahid N, Kharbach A, El-hassani A et al. Fetal outcome in emergency versus elective cesarean sections at Souissi Maternity Hospital, Rabat, Morocco Pan. Afr Med J. 2016;23:197.

9. Elvedi-Gasparović V, Klepac-Pulanić T, Peter B. Maternal and fetal outcome in elective versus emergency caesarean section in a developing country. Coll Antropol. 2006 Mar;30(1):113-8.

10. Berendzen JA, Howard BC. Association between cesarean delivery rate and body mass index. Tenn Med. 2013;106:35-7.

11. Kambale MJ. Social predictors of caesarean section births in Italy. Afr Health Sci. 2011 Dec;11(4):560-5.

12. Harlow BL, Frigoletto FD, Cramer DW, Evans JK, Bain RP, Ewigman B et al. Epidemiologic predictors of cesarean section in nulliparous patients at low risk. RADIUS Study Group. Routine Antenatal Diagnostic Imaging with Ultrasound Study. Am J Obstet Gynecol. 1995 Jan;172(1 Pt 1):156-62.

13. Turcot L, Marcoux S, Fraser WD. Multivariate analysis of risk factors for operative delivery in nulliparous women. Canadian Early Amniotomy Study Group. Am J Obstet Gynecol. 1997 Feb;176(2):395-402.

14. Burke N, Burke G, Breathnach F, McAuliffe F, Morrison JJ, Turner $\mathrm{M}$ et al. Prediction of cesarean delivery in the term nulliparous woman: results from the prospective, multi-center Genesis study. Am J Obstet Gynecol 2017;216:598.e1-11.

15. Joshua PV, Betrán AP, Vindevoghel N, Souza JP, Torloni MR, Zhang $\mathrm{J}$ et al. Use of the Robson classification to assess caesarean section trends in 21 countries: a secondary analysis of two WHO multi country surveys. Lancet. 2015;(3):260-70.

16. Abdel-Aleem H, Darwish A, Abdelaleem AA, Mansur $\mathrm{H}$. Usefulness of the WHO C-Model to optimize the cesarean delivery rate in a tertiary hospital setting. Int $\mathbf{J}$ Gynecol Obstet. 2017 Apr 1;137(1):40-4.

17. Ribeiro V, Figueiredo F, Silva A, Bettiol H, Batista R, Coimbra L, et al. Why are the rates of cesarian section in Brazil higher in more developed cities than in less developed ones? Brazilian J Med Biologic Res. 2007;40:1211-20.

18. Cavallaro FL, Cresswell JA, França GVA, Victora CG, Barros AJD, Ronsmans C. Trends in caesarean delivery by country and wealth quintile: cross-sectional surveys in southern Asia and sub Saharan Africa. Bulletin of World Health Organization. 2013 Dec;91(12):914-22D.

19. National Center for Health Statistics. User Guide to the 2010 Natality Public Use File. Hyattsville, Maryland: National Center for Health Statistics. Annual product 2012. Available

at http://www.cdc.gov/nchs/data_access/VitalStatsOnline. htm. Accessed January 20, 2016.

20. Ota E, Haruna M, Suzuki M, Anh DD, Tho LH, Tam NT et al. Maternal body mass index and gestational weight gain and their association with perinatal outcomes in Vietnam. Bull World Health Organ. 2011;89:127-136.

21. Souza JP, Gülmezoglu A, Lumbiganon P, et al. Caesarean section without medical indications is associated with an increased risk of adverse short-term maternal outcomes: The 2004-2008 WHO Global Survey on Maternal and Perinatal Health. BMC Med. 2010;8:71

22. Blondel B, Lelong N, Kermarrec M, Goffinet F. The National Coordination Group of the National Perinatal Surveys. Trends in perinatal health in France from 1995 to 2010. Results from the French National Perinatal Surveys. J Gynecol Obstet Biol Reprod (Paris). 2012;41:e1-e15.

Cite this article as: Ray A, Gopi A, Ray S. Comparing WHO C-Model generated C-Section probabilities to actual delivery outcomes in a tertiary care centre. Int J Reprod Contracept Obstet Gynecol 2018;7:229-33. 